\title{
RELATO DE OBSERVAÇÕES E CONVIVÊNCIAS NA SALA DE AULA
}

\section{Alessandra Vita de Araújo Vita}

\section{RESUMO}

No presente artigo narro minha inserção como pedagoga e professora substituta de $2^{\mathrm{a}}$ série na Escola Padre Francisco Silva da Rede Municipal de Campinas, quando assumo a responsabilidade por um grupo de alunos com histórias de rótulos, estigmas e pré-conceitos. Algumas questões que me inquietavam: mudar a imagem negativa que o grupo tinha de si mesmo, melhorar as relações no grupo, estabelecer democraticamente alguns princípios dentro do grupo. Um dos caminhos delineados para possibilitar essas mudanças no grupo foram as atividades desenvolvidas a partir do projeto de Ciências que denominei "Nossa Horta". O encontro com os colegas da escola nos momentos de reflexão conjunta foi um outro caminho que me possibilitou delinear outras estratégias.

\section{PALAVRAS-CHAVES}

Grupo; Democracia; Projeto

\section{TEACHER-STUDENT RELATION IN THE CLASSROOM}

\section{ABSTRACT}

In the present article I narrate my experience like substitute professor of 2do degree in the School Padre Francisco Silva of the Municipal Network of Campinas, when I assume the responsibility of a group of students that have histories of labels, estigmas and preconceptions. Some questions that troubled me: to change the negative image that the group had of itself, to improve the relations in the group and to establish democratically some principles within the group. One of the delineated ways to make possible those changes in the group were the activities developed in the project of Sciences that I denominated "Our Orchard". The gathering with other professors of the school at the moments of joint reflection was another way that it made possible to me to delineate other strategies.

\section{KEYWORDS}

Group; Democracy ; Project

\section{INTRODUÇÃO}

Cheguei até a escola EMEF ”Padre Francisco Silva” por meio de classificação realizada pela Prefeitura de Campinas. Participei de uma atribuição em 18/08/04 e fui contratada pelo período de 02/09/04 a 21/12/04 como professora substituta.

Quando entrei na unidade escolar (U.E.) no segundo trimestre para atuar como professora da $2^{\mathrm{a}}$ série B, encontrei as dinâmicas e os projetos interdisciplinares já em andamento: Grupo Trilharestórias (é assim mesmo Laura), Fanfarra Escolar, Grupo JOCAD, Orientação Sexual, Projeto Resgate, Projeto 


\section{PROCESSO ENSINO-APRENDIZAGEM: ALGUMAS ESPECIFICIDADES Grupo de Pesquisa em Ensino Superior}

Pré-vestibulinho, Programa: A escola é nossa, Basquete, Pró-dança, Projeto Mocambos (informática), Projeto Radio Escola.

Apesar da estrutura física se apresentar pequena, a U.E. possuía 15 classes de ensino regular de $1^{\mathrm{a}}$ a $8^{\mathrm{a}}$ série e 3 classes de suplência.

O envolvimento da comunidade nos projetos que aconteciam, mostrava o interesse da escola em estar realizando um trabalho com a parceria dos pais e alunos. Confesso que me senti um pouco apreensiva quanto à recepção e aceitação da equipe da Unidade Escolar. Fui bem recebida e orientada pela equipe administrativa e pedagógica quanto aos eventos e encontros que iriam acontecer e os que já estavam acontecendo na U.E. Com o decorrer do tempo fui vivenciando cada momento, nos diferentes sectores da U.E. como secretaria, sala de vídeo, biblioteca, e nos encontros de reuniões de estudos, TDIs (Trabalho Docente Individual) e TDCs (Trabalho Docente Coletivo).

A minha preocupação também foi em relação à recepção que os alunos teriam para comigo, pois o histórico apresentado pelas professoras da escola em relação à $2^{\mathrm{a}} \mathrm{B}$ não era dos mais favoráveis. Nessa sala haviam passado duas professoras, das quais uma pediu licença saúde e a outra pediu exoneração do cargo. Senti que os alunos ficaram estigmatizados, rotulados, devido à constante mudança de professoras. Ouvi também vários comentários por parte de alguns profissionais da escola a respeito da indisciplina e da desordem da sala.

Meus primeiros momentos com os alunos foram de conhecimento e adaptação. Fui recebida com entusiasmo e com um monte de perguntas a respeito da minha permanência até o fim do ano. Perguntaram se eu só ficaria um tempo e depois iria embora como havia acontecido com as outras professoras. Fiquei muito preocupada com estas perguntas, pois eu cheguei cheia de vontade de fazer a diferença na vida daqueles alunos e me deparei com uma situação de baixa auto-estima. As experiências vivenciadas pela $2^{\mathrm{a}} \mathrm{B}$ não haviam deixado lembranças construtivas e agradáveis, podia-se mesmo ver na expressão dos rostinhos dos alunos uma certa insegurança quanto à minha permanência e o meu bem querer para com eles.

Com o tempo busquei observar e ouvir as dúvidas e reclamações que a sala fazia, ouvi várias vezes de alguns alunos as seguintes frases: “Você não vai nos agüentar!”, ”Nós somos terríveis!”. Eu sabia que essa reação era comum, já que a $2^{a} \mathrm{~B}$ passou por períodos de grande adaptação e readaptação com duas professores e ficou um certo receio em receber alguém a quem eles pudessem se apegar e serem abandonados novamente.

Eu e os alunos fizemos um acordo. Conversamos sobre as atividades e coisas que eles achavam legais de estarem acontecendo na sala de aula e as que eles não achavam legais. Todas as conclusões 


\section{PROCESSO ENSINO-APRENDIZAGEM: ALGUMAS ESPECIFICIDADES \\ Grupo de Pesquisa em Ensino Superior}

conversadas entre os grupos foram anotadas pelos representantes dos grupos em seus cadernos de registros. Desta forma, tanto eles quanto eu, professora, nos sentirmos confortáveis e seguros em quanto aos nossos direitos, tendo a possibilidade de nos expressar com liberdade, acreditando em uma convivência democrática.

Resolvemos determinar um tempo de duas horas no final das aulas das sextas-feiras para conversarmos e trocarmos idéias com os grupos que compunham a turma da sala, sempre socializando dúvidas sobre as atividades desenvolvidas e sobre os acontecimentos da semana. Ficou combinado que poderíamos conversar e migrar para outros grupos de discussão, promovendo assim, a socialização da sala.

Essa primeira experiência com a sala me fez ver que esses alunos só precisavam ter base para se sentirem seguros e responsáveis para com suas próprias atitudes e decisões, sabendo que elas poderiam ter resultados tanto positivos, quanto negativos na convivência diária na sala de aula.

Foi neste momento de interação com a sala que surgiram dois convites. O primeiro convite, foi para participar do Grupo de Reflexão sobre Letramento e Alfabetização que estava acontecendo todas as quartas-feiras de manhã. O mesmo tinha sido instituído pela Secretaria Municipal de Educação de Campinas a partir do ano letivo de 2004. O segundo convite foi para entrar no Grupo de Trabalho (GT) e pesquisa coordenado pela $\operatorname{Prof}^{a} \operatorname{Dr}^{\mathrm{a}}$ Ana Maria Falcão de Aragão Sadalla, grupo que surgiu a partir do desenvolvimento na escola do projeto “Escola Singular: Ações Plurais”. Fiquei surpresa e me informei sobre o desenvolvimento deste projeto, que me despertou interesse, sendo uma oportunidade rica de estudar a ação e a reflexão sobre o que acontecia na sala de aula. As discussões a respeito do desenvolvimento desse trabalho haviam começado no ano de 2003, e somente agora em 2004 estaria sendo oficialmente colocado em prática. Com todos os esclarecimentos que tive ainda ficou uma dúvida, se eu entraria ou não no projeto, pois eu ficaria substituindo pouco tempo nesta escola. Pensei muito, o momento era realmente oportuno, afinal, a sala em que eu atuava precisava da minha vontade de estudar e desenvolver algo que realmente pudesse estar melhorando a interação, a cooperação e a auto-estima daqueles alunos que apesar de inquietos se mostravam interessados.

A minha preocupação em entrar no projeto de pesquisa era saber se eu teria tempo suficiente para estudar e me aplicar, para assim conseguir os resultados sobre a pesquisa que eu estaria iniciando sobre a influência e os benefícios na relação entre grupos na sala de aula.

Quando eu lembrava que eu estaria de passagem naquele espaço escolar, batia uma tristeza e um desestimulo que me incomodava muito. Foi neste instante que conversei com a Prof ${ }^{\mathrm{a}}$. Dr ${ }^{\mathrm{a}}$. Ana Aragão e com as minhas colegas professoras e percebi que deveria participar, pois esta oportunidade me 
permitiria auxiliar e ajudar meus alunos no processo de aprendizagem e eu estaria adquirindo mais experiência com as leituras, com os seminários e encontros da pesquisa. Foi neste momento que todos nós professores nos reunimos e escolhemos os temas a serem estudados e nos dividimos em grupos e subgrupos de estudos, para pensar no objeto a ser pesquisado e observado. Quando conseguimos nos centrar nos objetos, percebemos que aquela pesquisa renderia resultados e frutos incríveis, já que cada objeto escolhido pelas professoras-pesquisadoras complementaram e auxiliaram os estudos das outras colegas de pesquisa.

O nome do meu objeto é a Constituição de grupos na sala de aula e o motivo pelo qual o escolhi, foi a possibilidade de poder estudar os diferentes papéis que são assumidos em um grupo além de compreender como a relação grupal favorece a interação entre os integrantes na sala de aula.

Sabemos que cada pessoa é diferente da outra. Acredito que a interação dessas diferenças faz com que reflitamos e nos transformemos em pessoas melhores, com discernimento de perceber que nada é imutável, concordando assim, com a clássica afirmação de Lavoisier de que "nada se perde tudo se transforma”. E é diante desta possibilidade de transformação e melhora, que devemos valorizar a nossa participação nos diferentes tipos de grupos ao longo da vida. Segundo Pichon-Rivière (apud Madalena Freire, 1992 p. 59-61):

pode-se falar em grupo quando um conjunto de pessoas movidas por necessidades semelhantes se reúne em torno de uma tarefa específica (...) no cumprimento e desenvolvimento das tarefas, deixando de ser um amontoado de indivíduos para cada um assumir-se enquanto participante de um grupo, com um objetivo mútuo.

Segundo este mesmo autor, no grupo podem ser assumidos cinco papéis, que são: "líder de mudança, líder de resistência, bode expiatório, representante do silêncio e o porta voz” (Ibidem, 1992, p.62).

Madalena Freire estabelece a existência de dois tipos de grupos nos quais podemos estar inseridos. Um deles é o grupo primário, o da família, onde acontecem as nossas primeiras experiências. Esther Pillar Grossi (apud Madalena Freire, 1992 p. 71), diz que:

a criança, teve a sua existência ao desejo de dois (seu pai e sua mãe)... como expressa a frase de Lacan 'Todo o desejo é desejo do outro'. E o desejo repousa na articulação lógica das representações do que restou das vivências de alguém como recordações significativas.

Sendo assim, cada pessoa ocupa um papel dentro da família, ou de mediador, ou de silenciador, ou de ausente, etc... Esse papel associado pela pessoa, como lembra Madalena Freire (1992) tem que ser pensado com consciência e educado com o tempo, pois pode se cristalizar e tender-se à repetição mecânica. A mesma autora diz que os grupos secundários são aqueles que englobam trabalho, estudo, instituições.

(C) ETD - Educação Temática Digital, Campinas SP, v.7 , n. esp., p.96-102 , jun. 2006 - ISSN: 1676-2592. 99 


\section{PROCESSO ENSINO-APRENDIZAGEM: ALGUMAS ESPECIFICIDADES Grupo de Pesquisa em Ensino Superior}

A partir desse referencial, procuro compreender o grupo secundário, já que estamos tentando trabalhar a constituição de grupos em sala de aula. A $2^{\mathrm{a}}$ série B, como já falado anteriormente, foi uma sala com histórico de rótulos, baixa auto-estima, mas, apresentavam grande potencial de aprendizagem.

Desenvolvi um projeto de Ciências que denominei "Nossa Horta”. Comecei as atividades com o intuito de conseguir fazer com que os alunos se reunissem e se organizassem em grupos, levando em consideração as regras estabelecidas na sala.

A proposta de trabalho começou com uma pesquisa. Precisávamos escolher a planta que iríamos cultivar, para isso era importante saber qual seria o tempo de desenvolvimento delas, para assim poder acompanhar, registrar e discutir juntos o seu desenvolvimento, sendo que já estávamos no meio do segundo trimestre e teríamos apenas o tempo do terceiro trimestre para realizar estas atividades juntos.

No primeiro momento deixei que os alunos se organizassem por si. Mas, fui percebendo que não estavam acontecendo as tão esperadas interações e socializações. Ficou evidente que seriam necessárias algumas reformulações. Foi quando busquei orientação junto as experiências das minhas colegas professoras e da equipe de apoio da Universidade Estadual de Campinas que é composta pela Profa. Dra. Ana Maria Falcão de Aragão Sadalla, pelo Prof. Dr. Guilherme do Val Toldeo Prado, e por suas orientandas, que estiveram nos subsidiando e nos orientando frente às dúvidas que surgiram no decorrer das nossas observações.

A partir das sugestões recebidas, os grupos de minha sala foram reorganizados. Meu papel de mediadora favoreceu a possibilidade dos alunos estarem relacionando sempre os conteúdos estudados. Essa movimentação e mudança dos integrantes dos grupos foi muito interessante, pois criou um rebuliço entre eles. Aconteceu uma certa resistência em relação aos integrantes novos que mudaram de grupo, mas essa resistência foi sendo amenizada com a relação e o conhecimento do papel do outro no grupo, que foi se tornando parte essencial de transformações, tanto com suas opiniões, quanto com suas discordâncias. Madalena Freire nos lembra com sua fala que:

um grupo se constrói na organização sistematizada de encaminhamentos, intervenções por parte do educador, para a sistematização do conteúdo em estudo. (...) Se constrói enfrentando o medo que o diferente, o novo provoca, educando o risco de ousar (Madalena Freire, 1992, p.65).

O projeto "Nossa Horta” foi desenvolvido e planejado juntamente com os grupos da sala que tinham como objetivo a horta pronta e suas plantas desenvolvidas. Conseguimos realizar todo o processo, passo-a-passo. Cada grupo realizou suas pesquisas de como escolher a melhor planta, como saber qual era melhor época para se plantar, quais seriam os materiais necessários para formar uma horta. Todas as pesquisas realizadas nos diferentes grupos foram socializadas nas aulas de ciências, 


\section{PROCESSO ENSINO-APRENDIZAGEM: ALGUMAS ESPECIFICIDADES Grupo de Pesquisa em Ensino Superior}

cada grupo apresentou para a sala o resultado das suas pesquisas. Como atividade final do projeto, elaboramos juntos o projeto escrito da horta, produzindo um texto coletivo.

Essa experiência foi muito importante, tanto para os meus alunos como para mim como professora, já que me vi aprendendo mais que ensinando, a interação e a cooperação entre eles foi um dois aspectos que ao longo do projeto mais me impressionou. Nem pareciam ser os mesmos alunos que se mostravam inseguros e com medo de ousar, e se “achando os piores dos piores”, como já referido.

Com os relatos e registros das observações e conversas realizadas nos encontros da EMEF Padre Francisco Silva e com as primeiras amostras de resultados positivos socializadas no seminário que fizemos, pudemos constatar que conseguimos dar alguns passos, passos estes, que podem se multiplicar com observação, empenho e o aprofundamento teórico para o ano de 2005.

Vale lembrar que a equipe administrativa e pedagógica nos apoiou frente às necessidades materiais para desenvolver os projetos como, por exemplo, a "Nossa Horta"; que nos deu respaldo quanto à necessidade e disponibilidade para usarmos os espaços para a realização das nossas reuniões e encontros. $\quad \mathrm{O}$ espaço físico da U.E. é pequeno mas, a organização me fez sentir acolhida. Acredito que mesmo com a organização de horários para a utilização dos espaços seria interessante estar ampliando e construindo novas salas para a acomodação e a possibilidade de acontecer mais atividades paralelas nos mesmos horários dentro da U.E. facilitando e enriquecendo ainda mais o ambiente e a interação dos alunos.

Antes mesmo do desenvolvimento do projeto de pesquisa "Escola Singular: Ações Plurais”, já se sabia que a EMEF Padre Francisco Silva era uma escola com um histórico interessante de envolvimento e relacionamento com os alunos e com a comunidade ao seu redor. E agora com o envolvimento da pesquisa, pode-se ver que o que era bom melhorou ainda mais, pois se os pais já participavam da realidade da escola, agora estão com mais interesse e estão vindo à escola querendo saber quais são as dificuldades dos filhos, como eles estão se comportando. A melhora também aconteceu no envolvimento entre os membros da U.E., que ficou mais interativa, fazendo com que cada integrante tivesse uma postura mais questionadora sobre sua prática na escola e na sala.

(C) ETD - Educação Temática Digital, Campinas SP, v.7 , n. esp., p.96-102 , jun. 2006 - ISSN: 1676-2592. 


\section{REFERÊNCIAS}

ANDALÓ, Carmem S. A. O papel de coordenador de grupos. Psicologia USP. São Paulo. v. 12, n. 1,

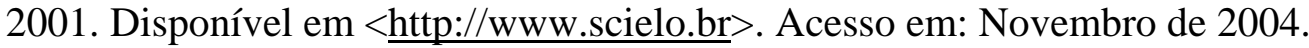

DE ROSSI, Vera Lúcia Sabongi. Desafio á escola pública: tomar em suas mãos seu próprio destino. Caderno CEDES, Campinas, v.21, n.55, Novembro de 2001. Disponível em:

http://www.scielo.br. Acesso em: Novembro de 2004.

FRANTZ, Walter. “Educação e cooperação: práticas que se relacionam” In: Sociologias: Dossiê Ciência e Tecnologia. Porto Alegre. N. 6, jul / dez. 2001. Disponível em http://www.scielo.br. Acesso em: Novembro de 2004.

FREIRE, Madalena. (org.) Paixão de aprender. Petrópolis: Vozes, 1992.

ZANELLA, A. V.; FILHO, K. P.; ABELLA, S.I. Relações sociais e poder em um contexto grupal: reflexões a partir de uma atividade específica. Estudos de psicologia. Natal. V. 8, n.1, jan / abril de 2003. Disponível em http://www.scielo.br. Acesso em: Novembro de 2004.

ALESSANDRA VITA DE ARAÚJO VITA

Pedagoga e professora substituta da $2^{\mathrm{a}}$ série da

EMEF Padre Francisco Silva, Campinas.

e-mail: learaujo@msn.com

ARTIGO RECEBIDO EM: 10/01/2006-05

Aceito para publicação em: 09/05/2006

(C) ETD - Educação Temática Digital, Campinas SP, v.7 , n. esp., p.96-102 , jun. 2006 - ISSN: 1676-2592. 